chemical properties expected of 'free fluorine. The compound row described is a fluorplumbate of the composition $3 \mathrm{KF}$. IIF. $\mathrm{PbF}_{4}$. It may be obtained by thiee methods. The first consists in treating the freshly precipitated hydrated oxide of lead, $\mathrm{Pr}_{5} \mathrm{O}_{7} \cdot 3 \mathrm{H}_{2} \mathrm{O}$, a substance described by Dr. Brauner in the year 1895 . with a mixture of hydrogen potassium finorile and hydrofluoric acid. The fluorplumbate is separated from the lead difuoride simultaneously formed by crystallisation from hydrofluoric acid. The second method consists in substituting fuorine for oxygen in the plumbates of Fremy. Peroxide of lead and caustic potash, in the proportions of the compound $3 \mathrm{KOH} . \mathrm{PbO}_{2}$, are fused in a silver crucible; the product is moistened with water, and then added gradually to excess of pure hydrofltoric acid. The filtered solution is evaporated to the crystallising point in a current of air, and as soon as crystals commence to form is placed in a vacuum desiccator. Crystals of the salt are then deposited. The third method consists in displacing the acetic acid in lead tetracetate by fuorine. One molecular equivalent of lead tetracetate is added to three equivalents of hydrogen potassium fluoride, $\mathrm{HF} . \mathrm{KF}$, dissolved in hydrofluoric acid; crystals of potassium fluorplumbate are formed upon evaporation, either in the air or in vacuo. Analyses of the crystals prepared by all three methods indicate the composition $3 \mathrm{KF}$. HF. $\mathrm{PbF}_{\mathrm{d}}$

The needle-shaped crystals, which freqrently attain the length of a centimetre, and are grouped radially, have been found to be in all probability monoclinic in symmetry, and ismorphous with the analogous fluorstannate described by Marignac.

Potassium fluorplumate is permanent in dry air, but becomes brown in moist air, heing decomposed by water, with formation of hydrated peroxide of lead, hydrogen potassium fluoride, and free hydrofluoric acid. The effect of heat upon the salt is most interesting and important. The experiments should be carried out in a platinum tube. At $100^{\circ}-110^{\circ}$ the crystals remain unaltered. At $200^{\circ}$ hydrogen fluoride commences to be evolved in small quantity. When subjected to a much highe: temperature, after previous heating for several hours at $230^{\circ}-250^{\circ}$, a gas commences to be evolved endowed with the odour ascribed by Moissan to fluorine. This occurs much below a red heat. The gas liberates iodine in such large quantities from iodised starch paper as to cause it to be devosited in crystals, and small crystals of silicon held in the open end of the tube not only burn with a vivid incandescence, but even with explosive violence. There can, therefore, be no question that the gas is free fluorine, and it would thus appear that Dr. Brauner has discovered a trustworthy purely chemical process of isolating the element. Potassium fluorplumbate lo:es its hydrogen fituride almost completely at $230^{\circ}$, without losing more than a trace of fluorine from the lead tetrafluoricle. Any small trices of hydrogen fluoride subsequently evolved along with the fuorine at the higher temperature may be readily removed by Moissan's method of passing the gas over potassium fluoride.

Dr. Brauner has already obtained evidence of the existence of a whole series of fuorplumbates, analogous to Marignac's fluorstannates, and is now engaged in studying the sodium salt. A. E. Turton.

\section{A SURVEY OF THE ENGLISH LAKES}

$A T$ the last meeting of the Royal Geographical Society a paper was read by Dr. Hugh Robert Mill, on the Lake 1) istrict of North-western England, of which the following is an abstract:- The lake district is a remarkably definite and symmetrical geographical unit. It may be roughly described as a circular mass of elevated land, highest in the centrc, and furrowed by a series of valleys running from the centre toward the circumference like the spokes of a wheel. Most of these valleys contain long narrow lakez of considerable size, and of a different type from the small round mountain tarns which also occur in the district.

An account was given in the paper of the methods employed for ascertaining the depth and fixing the position of each sound. ing, and for mapping the resulting information. The lakes considered were Windermere, Ullswater, Coniston Vater, Wastwater, Ennerdale Water, Buttermere and Crumnock Water, Derwentwater, Bissenthwaite Lake, and Haweswater, each of which was found to have certain special characteristics which distinguished it from all the others. The soundings were

No. I 286 , VOL. 50$]$ carried out by the author, assisted by Mr. E. Heawood, Mr. Shields, and others.

There are two main types amongst these lakes, the shallow and the deep. The former, including only Derwentwater and Bassenthraite, are the broadest of all the lakes; they average is feet in depth, their mean depth being only 25 per cent. $f$ the maximum depth, a smaller ratio than for any other lakes. The bed of these lakes may be roughly described as an undulating plain, grooved and ridged into shallow h.llows, and low shoals running pirallel to the long axis of the lake. The configuratirn suggests that they may have been shallowed by glacial accumulations.

The second, or deep type, the shallowest of which has an average depth of 40 feet, and in which the average depth varies from 36 to 61 per cent. of the maximum depth, comprises alt the nther lakes except, possibly. Ennerdale, which combines the characteristics of hoth types. They are long, narrow, some. times winding like Ullswater, or slightly curved in outline like Wastwater and Haweswater. The most characteristic lie in lung narrow valleys with steeply sloping sides, and the slopes are continued under water with almost equ il steepness, in some cases with greater steepness, and terminate in a nearly flat floor. The typical form of this class of lake is thus a steep-sided flathottomed trough, diversified along the slopes by the still steeper conical mounds of débris thrown down at the mouths of streams. In Haweswater the largest example of a delta occirrs, nearly cutting the lake in two; while But'ermere and Crummock, lying in une uniform valley, are entirely separated, probably by the same action, and Derwentwater is also divided from Bassenthwaite by a broad alluvial plain. Although most of the lakes show only one clearly defined trough, the two largest are divided into distinct basins. In Windermere, the shoal on which Belleisle and the other islands of Bowness, rise separates the deep and wide upper basin from the less deep and much narrower lower basin. In Ullswater each of the three reaches of the lake contains a definite basin separated from the others by broad or narrow bars. From one of these the island of Ilouseholm rises, a mass of strongly glaciated rock ; but while the position of the basin to the south of it seems to confirm the glacial theory of the excavation of the hollow, the hollow to the north of the island is so situated as to make its origin by glaciation somewhat difficult to understand.

Three of the lakes have depths which descend below sea. level. In Uastwater $2 \mathrm{I} 7$ acres lie beneath sea-level, so that if drained to that extent it would present the appearance of a lake still 58 feet in depth at one point. Windermere, if similarly drained, would show a northern lake 31 miles long with a maximum depth of 90 feet, and 3 miles further south a narrower like 1 mile in length and only 14 feet deep at its deepest, while south of this there would be a still shallower lagoon half a mile long. In Coniston reduced to sea-level there would probably appear one narrow lake $2 \frac{1}{2}$ miles long and 42 feet in maximum depth. All the other lakes are situated at such elevations that they do not approach sea-level in their greatest depths.

Altogether, the lakes which have been sounded and mapped cover an area of 20 square miles of unexplored territory. Contoured maps of the ten lake basins under consideration have been supplied to the Ordnance Survey for incorporation on the official maps of the country.

\section{THE RECENT DISCOVERY OF FOSSIL REMAINS AT LAKE CALABONNA, SOUTH AUISTRALIA.}

I.

FrOM time to time notices have appeared of a remarkable discovery of fossil bones at Lake Mulligan in the interior of South Aust:alia, but so far there has been no connected statement of what has been done in the way of developing the discovery. For reasons which will be evident, it is not yet possible to announce the results with anything more than a rough approximation, which leaves many interesting questions unsolved, or even untouched. Still, in view of its palxontological importance, it seems desirable that any available information should be given without further delay.

Necessarily a fragmentary and imperfect record, I trust the following account will, at least, afford evidence that the authorities of the South Australian Museum are fully alive to the interest of the issues involved, and that, so far as their not 1 By Dr. E. C. Stirling, F.R.S., C.M.G., Hoz. Director, South Australian Museum. 